\section{Forget This Article: On Scholarly Oblivion, Institutional Amnesia, and Erasure of Research History}

\author{
Mary Hafeli \\ State University of New York, New Paltz
}

\begin{abstract}
Eternal return is a condition that characterizes the world of art education and its scholarship, though it seems that the phenomenon goes largely unnoticed by many writing in the field today. The failure to name our work as part of an existing family of ideas, with themes that may date back to the years 1950-1970 or earlier, has implications not only for how we understand the evolution of the field's knowledge base but also for the sophistication and depth of our scholarship. This article reveals how, as a custom, contemporary researchers in art education rarely reference early research from the field. Citing evidence from personal experience and from an analysis of citations in research articles published over the past 5 years in Studies in Art Education, I present reasons why the condition exists generally in art education scholarship. Finally, I argue that our custom of not acknowledging early research results in a fragmented, incoherent knowledge base, a condition that may ultimately deter substantive refinements in our practice.
\end{abstract}

The idea of eternal return is a mysterious one, and Nietzsche has often perplexed other philosophers with it: to think that everything recurs as we once experienced it, and that the recurrence itself recurs ad infinitum! What does this mad myth signify?

\section{—Milan Kundera, The Unbearable Lightness Of Being, 1984}

Eternal return, the idea that events and experiences are repeated over time, is an ancient concept dating back to the Egyptians. Puzzling to philosophers, a useful theoretical tool for historians and physicists, eternal return can be considered a means by which people learn from the past. This happens, for example, when we use our insights about historical events as an interpretive lens to understand seemingly similar, present-day occurrences as actions projected or echoed across time and within different contexts.

Eternal return can also be considered a condition that has come to characterize the world of art education and its scholarship, though it seems that the phenomenon goes largely unnoticed by many of us writing in the field today. This lack of awareness is evident when we fail to acknowledge that scholars from the field's history may have already explored, in some form or another and through public presentation, questions and projects related to the topics we engage as scholars working today. The failure to name our work as part of an existing family of ideas - a family with past generations, historical lineage, and roots-has implications not only for how we understand the evolution of the field's knowledge base but also for the sophistication and depth of our documented collective insight, or scholarship. ${ }^{1}$ In this article, I examine the concept of eternal return by revealing its presence in recent scholarly inquiry,

\begin{abstract}
1 The phrase eternal return has different meanings in different disciplinary contextsfor example, physics, theology, philosophy, and history. Even within a single discipline there is not always a uniform interpretation of the idea, and among multiple disciplines, definitions may be shared, blended, or blurred. A detailed analysis of Nietzsche's "eternal return" falls outside the intent and purpose of this essay. I reference Kundera's literary investigation of the concept - which chronicles the experiential consequences of eternal return-because the novel focuses on "lightness of being," a state that occurs when people do not recognize, or may fail to benefit from understanding,
\end{abstract}

(continued) 
the implications of their repetitious actions, drives, and desires. I equate "lightness of being" with a potential "lightness" of the field's insight into enduring and perennial issues inherent in the practices and demands of art teaching and learning. This belief is based in the fact that much of our current research fails to cite, thus does not thoughtfully build upon, related historical precedents. In clarifying this distinction, I acknowledge comments on an earlier draft of this essay from one of the manuscript's reviewers.

2 Zimmerman,

Chalmers, Hausman, \& Stockrocki (2007).

3 As Chalmers (2006) reports, Smith said at the time: "we live in a preeminently fast age', where 'we think no more, but perhaps less; we have no time to think, but go crashing on to save ourselves from being crushed in the hurry of progress'” (p. 292).

${ }^{4}$ For example, more than 35 years ago Efland (1971) wrote: The tragedy that our recent history shows seems to be that art education trades off one set of values for another. We seem foredoomed to wander from one rallying call to another. Between the thirties and

(continued) citing evidence from personal experience as a researcher and from an analysis of research articles published over the past 5 years in Studies in Art Education. I then present some reasons why the condition exists more generally in the field's ongoing scholarship. Finally, I argue that our custom of not explicitly acknowledging, connecting to, and building upon the work of other art education scholars, particularly those from the more-than-recent-decade past, results in a fragmented, incoherent disciplinary knowledge base-a condition that ultimately may slow the deepening of our collective insight and deter substantive refinements to the field's evolving theories and practices of art teaching and learning.

\section{The Eternal Return of Eternal Return in Art Education Scholarship}

Others also have noted the current lack of regard for antecedents in art education scholarship. At a National Art Education Association (NAEA) conference presentation in March 2007 titled "Old Wine In New Bottles: What is Wisdom in Art Education?" similar arguments were made. ${ }^{2}$ And in the Summer 2006 issue of Studies in Art Education, guest editor Graeme Chalmers wrote:

Not only do we easily cast past events aside ... we do the same with people and ideas; we ignore the historical precedents. We become suspicious of reading lists for graduate level courses that list too many pre-1996 books and articles. We weed older books from our libraries and personal collections ... we jump on new bandwagons before exhausting the possibilities of the preceding wagons." (Chalmers, 2006, p. 291)

Chalmers, himself not guilty of ignoring past voices in the field, reminds us that our current institutional obsession with new practices, and the breakneck speed with which we rush to adopt and discard conceptual rationales, was also noted by Walter Smith in an address to Massachusetts art teachers over 130 years ago. ${ }^{3}$ And, in regard to our more recent past, a number of editorials and commentaries in NAEA journals published over the last 50 years evidence the concern that lack of historical connectivity and depth among topics of scholarship and practice has repeatedly been part of the field's zeitgeist, at various points in our history. ${ }^{4} \mathrm{How}$ is it that art education scholars, as a practice, do not seem to extend their reviews of relevant works to integrate the historical research literature that stands to inform contemporary lines of inquiry? In what follows, I describe my own professional experience with this phenomenon.

\section{Scholarly Oblivion-A Confessional Tale}

As an artist and art teacher in the 1980s, I was intrigued by the idiosyncratic ways in which the children and teenagers in my classes went about making their art works. ${ }^{5}$ During my graduate studies in the 1990s, past anecdotal observations about young people's studio processes became research questions and, eventually, a qualitative, case study dissertation. Part of this work, of course, involved an extensive reading of "the literature" to find empirical studies and 
theoretical and philosophical works that surrounded and contextualized my research. ${ }^{6}$ I found then that conducting a literature review is a bit like finding friends or discovering relatives you did not know you had. These connected writings give us new perspectives about our work and these new considerations, hopefully, make the work better-more thoughtful, robust, and fully realized. As a novice researcher, I wanted to be sure I had searched extensively, read widely and deeply about my topic - for this is what I was told was in the tradition of scholars. I didn't want to miss anything that may have been relevant. Or leave anyone out who should have been included.

For the dissertation fieldwork, I spent a semester in the seventh-and eighthgrade classes of two middle school art teachers to try to find out, among other things, how students thought about their studio works as they made them. I wanted to understand what happened in the translation of the teachers' "given" assignments as students formed personal intentions for their works; I was particularly interested in the push and pull of teachers' goals and agendas for the learning of their students as they became aware of the students' own goals for their artworks. ${ }^{7}$ In analyzing and interpreting different layers of data, I found a particular form of resistance that was necessary for students to maintain if they were to develop independent judgment as artists, in the context of set assignment guidelines or criteria given by their teachers. Resistance is an oppositional quality, and I found that students who exhibited this kind of independent thinking defined their own artistic desires and intentions, and relied on a sense of autonomy, in finding and solving problems and making aesthetic decisions in their studio works.

Over 50 years ago, in an article published in Research in Art Education, 7th Yearbook (1956), ${ }^{8}$ Manuel Barkan and Jerome Hausman reported much the same thing in their study of creative behaviors of students making works in art class. But I learned about Barkan and Hausman's study not through my own review of related literature. I know about this work only because at the end of an NAEA conference session in which I was presenting my dissertation findings, Jerry Hausman raised his hand and said, "You know, I'm so excited to hear about your research. Did you know that Manny Barkan and I found something quite similar years ago in a study we did?"

My excitement about this connection quickly turned to embarrassment at not having cited the Barkan and Hausman research. When I later tracked down the article I was delighted that here was a study—on identifying "level of involvement" as a component of creative behavior in arts practice-that described a phenomenon similar to what my study found. Barkan and Hausman's research gave me a new way to look at and interpret my findings, almost 50 years later, and "new" language with which to describe and name them. The researchers' differentiation of the "official task," or that which is "suggested or assigned by the teacher," and the "private task," or the student's "perception of his own task," and their hypothesis that "children exhibited behaviors of high involvement when the 'official task' coincided with their 'private tasks'" (Barkan \& Hausman, 1956, p. 138), crystallized the context that surrounded the kinds of artistic resistance and instructional negotiation I had identified. The obvious

the sixties we went from child-centeredness to discipline centeredness, and now we are on the move again searching for another alternative (p. 24). Blandy (2008), offering a more optimistic view, writes that: While the field of Art Education has not yet conceptualized and implemented formal genealogical projects, members of the field do have an enduring appreciation, affection, and critical orientation to the myriad and complex networks of relationships that define who we are as individuals and as a collective (p. 5).

5 I noticed early on that, far from responding as a "class" to whatever I thought I was teaching them, my students had individual ways of working and took distinctly different approaches to thinking about the works they were creating. Some identified fixed themes and subjects at the outset while others liked to let narratives evolve and shift directions. Some loved to work with clay or paint or electronic media_or a needle and threadwhile for others this clearly wasn't their "thing." Some seemed to think in line, others in colors or textures, or forms and structures, weight and balance. Some worried about

(continued) 
following assignment guidelines closely to "get it right" ("Is this right, Miss H.? Is this the way we're supposed to do it?"), while rightness for others had to do with not worrying much about anyone's guidelines but their own.

6 Although "the literature" is a concept we take for granted, in practice "doing a literature review" can take many forms and can reveal contradictory assumptions about what constitutes an acceptable body of work to be reviewed. What we mean when we use the term is anything but clear as far as purpose and depth and breadth of content over time and across disciplines.

7 For a full description of the study and its methods see Hafeli (1999, 2000, 2001).

8 Research in Art Education, 7th Yearbook (1956) is one of three NAEA research compendia $(1954,1956$, 1959) that preceded Studies in Art Education.

9 The analysis focused on publications of empirical research, both qualitative and quantitative and including studies that used, among other approaches, ethnographic, case study, grounded theory, phenomenological (Huberman \& Miles, 2002),

(continued) irony is that although new to me at the time, the language was historically established through publication in the leading art education research journal of the 1950s. These operational terms were new in 1956 and took root through public reading, interpretation, and debate. Then they were "lost" and, 50 years later, "found" "anew." In what I thought at the time was a rigorous literature review, I had found only a few studies that were directly related; not one of these was as germane as the study by Barkan and Hausman. But I had not discovered this work-it was given to me; I learned about it by accident, not by design. And had that not been the case, I would still be oblivious to its presence in the literature that is related to a now ongoing area of personal inquiry.

This story is one small example of how eternal return and scholarly oblivion operate. Scholarly oblivion stems from the failure to understand that recurring themes, issues, and concerns are part of any field or discipline and that they permeate the trends and pendulum swings of not only a field's practices but also its research questions. Art education researchers are continually carrying out seemingly original, well-documented work that, without much historical citation, revisits issues that were addressed years ago. In a sense, we engage in the practice of collectively forgetting what came before. By not citing these studies we are, in effect, erasing the ideas — and silencing the voices - of those scholars in the field who preceded us.

\section{Institutional Amnesia}

What and where is the evidence for these claims that contemporary thought and scholarship in art education routinely disregard historical precedents? To explore this question with a focus on recently published empirical research, I undertook an analysis of reference lists for studies published over the past 5 years in Studies in Art Education. My aim was to determine how far back in time we typically go as contemporary researchers in our citations of literature pertinent to our topics. I counted the number of articles for which the primary purpose was to report empirical studies. ${ }^{9}$ From a total of 100 full-length articles, 43 (43\%) were empirically based, with an average of 34 items on the reference lists. I then tallied the number of references cited in the articles (1449) and the number of those references that dated to before 1980. For empirical studies published over the past 5 years, with a total of 1449 references, $138(9.5 \%)$ of the cited works were published prior to 1980 .

The fact that over $90 \%$ of the references cited in recent, empirical, art education research articles were for scholarship produced in the last 25 years did not seem odd, for that meant that about $10 \%$ of the citations represented scholarship from the '70s or before. However, when I reviewed the 138 cited works from the 1970s and earlier I found that more than half (66\%) were published in the ' $70 \mathrm{~s}$ - of these, most were from the late ' $70 \mathrm{~s}$ - with only a few from the ' 60 s (20\%) and ' 50 s (7\%). To put this finding in context, just $3 \%$ of the 1449 references cited in recent articles about empirical research highlighted scholarship produced prior to 1970 . This finding spurs two critical questions: Where, in our present day institutional memory, is the scholarship produced during the years of 1950-1970 and why is it not cited in current writing? 


\section{Unnecessary Remembering, Necessary Forgetting}

There are multiple reasons why researchers writing today may, deliberately or unwittingly, ignore studies from art education's research history that relate to our own areas of inquiry. First, discounting relevant scholarship from the past can be linked to two modernist characteristics that persist in culturally defining the field-Walter Smith's "fast age," which has only intensified over time, and its accompanying infatuation with hypercurrency ${ }^{10}$ in ideas and ideals. Postmodernism, at least in theory, had it that we should be acknowledging, revisiting, reinterpreting, and recontextualizing much more of our histories than that of the past 10 or 20 years. But in our current practice of empirical inquiry in art education, with our reference lists consistently excluding temporally distant yet potentially related historical antecedents, we seem to have sidestepped that principle. ${ }^{11}$

Hypercurrency abounds in places where novice researchers learn the tools and craft of research, and this is a prime locus for the lack of attention to art education's early scholarship. In graduate schools, for example, common advice for preparing literature reviews is to begin by searching for sources written within the past 5 to 10 years, or to look as far back as necessary to understand the context, key studies, and research methodology of one's topics and questions. Beginning researchers are trained in using the most technologically up-to-date databases for their areas of inquiry, such as Education Full Text and Art Full Text in art education, and these databases in themselves have historically been biased towards current scholarship. ${ }^{12}$ Published guides for writing literature reviews (Galvan, 2006; Hart, 1998) recommend mapping the most current research, but they also direct scholars to identify and cite historical landmark studies. Galvan advises researchers to determine the historical "landmark" or "classic" scholars and studies by looking for names and citations that are repeated in multiple sources. Hart recommends a similar approach through citation analyses, where the researcher examines the reference lists of related studies to identify the publications that appear most frequently. Hart's and Galvan's advice makes sense for education research and social sciences fields that actively acknowledge, in current scholarship, the landmark studies from the field's more distant past. But given the analysis above, how would any of us writing in art education today recognize the historical landmarks, when 30 years of potentially "classic" studies do not show up in the past 5 years of our own professional organization's research journal?

A second reason we neglect early research may have to do with a propensity for blazing new trails instead of cultivating and broadening, with multiple and diverse perspectives, established paths of inquiry. As scholars in a disciplinary field of thought and action that has long rewarded such qualities as originality and creativity, and iconoclasm, we aim for uniqueness. We seem to find replicating past studies - a practice that for other fields has served to deepen understanding of relevant concerns and topics - unnecessary and redundant. ${ }^{13}$ We consider revisiting historical art education topics to be less heady than pioneering or introducing new-or at least new to art education-themes, philosophies, and methodologies. We consider retooling or building on older narrative (Clandinin \& Connelly, 2000), and/or portraiture (Lawrence-Lightfoot \& Davis, 1997) methodologies and tools of data gathering, analysis, interpretation, and presentation. In using the term empirical I do not mean simply studies based in narrow positivistic research orientations. I use the term as Schwandt (2001) defines it-studies that exhibit as a primary function or feature the systematic gathering, analysis, and interpretation of observed or experienced (lived) phenomena, or data. I included all full-length articles that devoted at least half of the text to describing research question(s) investigated and their relation to existing research, the method(ology) of the study (including qualitative, quantitative, and mixed methods), and the analysis, interpretation, and implications of findings. Twenty issues-Winter, 2007 (Volume 48, Number 2) to Spring, 2002 (Volume 43, Number 3)—were reviewed. I chose Studies in Art Education because it represents peer-reviewed scholarship that our national professional organization considers to be worthy of publication and because it is the most widely dissemi-

(continued) 
nated of the field's art education research journals. Historically speaking, Logan (1975) credits the NAEA with, in the early ' 50 s, choosing to "take the leadership" to encourage research in art education at a time when scholarly studies in the field were, and had historically been, few (p. 8).

10 "Hypercurrency" (byper-over + currency - present time) refers to a well-documented public obsession with culturally perceived temporal edginess, newness, novelty, and speed with which we produce and consume. Additional evidence of this current state is the backlash "slow movement" and its accompanying cultural artifacts like the magazine Real Simple and the growing public interest in and demand for slow foods, slow travel, yoga and meditation, and other means of slow-ness.

11 Although the analysis was limited to the past five years of empiricallybased research articles published in Studies, I would not be surprised if a similar pattern was found for both nonempirical works from the same issues and contemporary research published during this time in other art education journals.

(continued) theories from the field to be less innovative and groundbreaking, and ultimately less noteworthy, than inventing our own. There has been little recent interest in systematically searching out, analyzing, synthesizing, and re-engaging topics and findings from art education's early research. For some, the question may be "Why bother?"14

This attitude in the field is not new. Its effects were noted a quarter of a century ago by Rush (1984), who wrote in a Studies editorial,

The resulting idiosyncratic nature of art education research comes as no surprise, but it is surprising even in comparison with other areas of education. The lack of systematic and coordinated research programs in our field is not only disappointing, it is stifling its professional growth.

Rush's observation, echoed more recently by Zimmerman (1996) and Burton (1998), conveys an earlier vision and hope for research in the field, that systematically designed investigations based on critical questions and involving multiple teams of researchers would provide a sophisticated, cumulative network of related findings for the purpose of directly impacting what art teachers actually do with young people in art classes. As McFee (1966) and others at the time saw it, "each bit of information adds something to the dimensions known" to "help us clarify our efforts in attempting to increase artistic awareness among those we are entrusted to educate" (p. 2). These earlier hopes, that research would not simply expand or substitute in our consciousness one set of pedagogical understandings and approaches for another, but would also provide an element of coherence and depth to our knowledge base, and improve instructional practice as well, have not been borne out over time. While coordinated and complementary research programs have existed at different points in our history, there have not necessarily been attempts within those efforts to systematically search out, analyze, synthesize, and bring to the forefront relevant findings from art education's early research, to forge those potential connections and relationships. ${ }^{15}$

A third reason that we fail to acknowledge early research as we conduct our own may have to do with another communal practice considered to be characteristic of our time - that of forgetting. Like eternal return, forgetting as a state of social existence is infused in our contemporary cultures. We are living, as literary critic Charles Baxter (1999) puts it, "in an age of forgetting." Baxter writes,

It's possible that in the last part of the twentieth century, we are pioneering a new kind of literature, a literature of amnesia, as we assemble the fragmentary texts of forgetting. This new literature is probably one side effect of data nausea, of which narrative minimalism may be another. If memory stands against death, forgetting stands against data. (p. 154)

Is our neglect of past scholarship in art education a symptom of "data nausea"? 16 Is there just too much to sift through that we do not even attempt detailed historical analyses of the topics and findings of previous art education research? Or is it that, in art education, we shift topics of essentiality so frequently that 
we don't realize-we institutionally forget - that we are channeling and recycling historical themes, problems, and questions? Perhaps changing conceptual courses and taking on different philosophical identities in this way necessitates the kind of institutional amnesia that makes "new" knowledge possible. Maybe many of the "old" topics have run their conversational course. ${ }^{17}$ But what are the ramifications of not remembering, of erasing, our research history? When are scholarly forgetting and historical amnesia acceptable, even desirable, practices? ${ }^{18}$ And when, on the other hand, do they lead us to the kind of oblivion and ignorance that actually thwarts the depth and sophistication of our scholarship?

\section{Rethinking a Literature}

Today, we don't know whether a consensus about what might constitute a thematically robust and networked knowledge base-one that is informed by an overarching understanding of conceptual and methodological gaps and needs in the field's scholarship, and one that provides thoughtful implications for affecting what teachers and students do daily in art classrooms-is even possible. ${ }^{19}$ But if we could come to such a consensus, what might be done to reconsider past scholarship in art education and bring its relevant layers forward in time, to coexist with and provide added significance to our contemporary pursuits? A first step, one that would begin to address the lack of historical coherence within and across our topics of inquiry, might be to invite teams of researchers to produce a series of literature reviews based on early research that addresses areas, issues, and concerns that are currently critical to our content and practice, and that could be of particular relevance to art educators' contemporary lines of inquiry. Art education, unlike other subject areas in education, lacks a collection of comprehensive syntheses of the topics, methodologies, theories, and findings of past studies - one that gives deliberate attention to early research. Unlike the comparatively extensive published descriptions of historical key figures, movements, classroom practices, and purposes for art education, and unlike early and more recent attempts to articulate agendas for future research in the field (for historical examples see Hartman, 1961 and Arnstine,1965; for more recent ones see Zimmerman, 1996), there is no systematic, detailed comparative analysis of topics, methods, and findings in our comprehensive art education research history that dates to and includes the present. Topical syntheses have recently been published in art education research handbooks such as the International Handbook of Research in Arts Education (Bresler, 2007) and Handbook of Research and Policy in Art Education (Eisner \& Day, 2004), but it was not the particular purpose of these compendia to search out and review early scholarship with the degree of detail necessary to understand historical patterns of methodologies, and specific findings, that might be relevant to our scholarship today.

Some earlier syntheses also exist, and these need to be interpreted with some understanding of the philosophical, world-view orientations and values of the authors who made selections about what studies to include, the times in which the reviewers lived, and the particular purposes or limitations of the syntheses. For example, an early review done in 1940 by Strange (in Davis, 1967, 1971;

12 At present Education Full Text, Art Full Text, and ProQuest Education Journals collectively contain full-text articles from art education journals such as Studies dating back 25 years at most. ERIC contains citations for art education journal articles and research reports dating to 1970 , but not all documents are available in full text. Things have improved with the advent of JSTOR, Education Index Retro, and Art Retrospective, which contain full-text issues of journals that date back to their inception.

13 Meier (1997), writing as the editor of the American Journal of Political Science, highlights the value of replication studies in social science research: "publishing research attempting to replicate, extend, or cross validate earlier studies will encourage authors to exercise greater care in their published work, preserve their data, facilitate discussion among scholars, and generate a more comprehensive research literature." He goes on to say that replication studies "encourage the discipline to become more cumulative" and that "[e]ncouraging replication should motivate people to read each other's work and to

(continued) 
talk to each other more, rather than allow the average journal article to languish after publication, never to be cited by anyone" (B7).

14 This is a legitimate response for researchers whose lines of inquiry are simply not addressed in early art education research. However, seemingly and relatively "new" topics—such as multicultural and social justice art education, interdisciplinary teaching and learning, action research, research on the effects of learning in art on learning in other subject areas, and collaborative art production practicesthat have been "introduced" within the last decade or so were originally addressed early on in art education's research history (see, for example, Beittel \& Lowenfeld, 1959; Freyberger, 1956; Lanier, 1959; Montgomery,1959; Russell,1956). These topics continued to be studied, at various times, prior to 1970 (see Bolton, 1969; Eisner,1969; Fischer, Irons, \& Fischer,1961; Hoepfner, Silverman, \& Hendricks, 1969; Neperud,1969; Salome, 1968).

15 Consider Discipline Based Art Education (DBAE) as an illustration. Clearly, the plethora of studies

(continued)
Hamblen, 1989) summarized "scientific investigations relating to art" during the years 1883 to 1939 . Davis $(1967,1971,1977)$ summarized the trends in topics but not, in comprehensive detail, the findings, of specific studies carried out between 1883 and 1972. Other examples include targeted analyses, such as Hamblen and Smith's (1994) review of 30 years of Studies in Art Education (vols. 1-33) in search of a particular "research art style"; occasional Studies editorials or commentaries that, like Burton's (1998) survey report, analyze, and categorize common research topics and/or methods of the times (for historical examples see Beittel, 1961; Chapman, 1978; Ecker, 1965; Hausman, 1959); and other essays and reports that analyze in greater detail the thematic research trends of the day or then-recent decade(s) (Arnstine, 1965; Barkan,1957; Hamblen, 1989; Hardiman \& Zernich,1976; Hartman,1961; Hoffa,1987; Lanier,1974-75; McFee, 1960).

What forms might future syntheses of early art education research take and how might they be organized and positioned? First, decisions would need to be made about the specific questions and purposes particular reviews might address, and about how to focus the investigations and determine boundaries. Should these syntheses be systematic, where a research question is clearly defined and the author seeks to include all prior research that is relevant? Or should they be conceptual, where the purpose is to "gain new insights into an issue" through integrative, theoretical, empirical, and/or methodological lenses (Kennedy, 2007, p. 139)? Kennedy describes some of these distinctions in detail, and discusses the differences between systematic reviews that ask what is known about a topic and conceptual ones that ask more nuanced questions, such as "why we don't know more" (p. 139). She also compares the values and limitations inherent in various approaches researchers might take in conducting literature reviews. Any efforts to seriously revisit early research in art education would benefit from first attending to these issues of purpose, focus, limitations, and forms of presentation.

Obviously, an initial step in all of this would be to systematically build a fulltext database, to make accessible early publications of art education research. NAEA would need to reissue the research Yearbooks that were published in the ' 50 s before Studies in Art Education was launched-in these three publications alone are 38 research articles encompassing both theoretical and empirical inquiry. Those articles, along with the 131 articles from the first 10 years of Studies, and art education research published in books from the same time period, could provide a base and starting point for generating questions and focusing individual syntheses.

I do not mean to suggest that the areas of investigation, specific questions, methodological approaches, and findings from every early study currently absent from our consciousness would be useful or even related to our contemporary lines of inquiry. Some titles found in early issues of Studies and in the research Yearbooks would seem conceptually inconsequential to researchers today, and some of our current topics may not have obvious historical precedents. Moreover, research methodologies, like philosophies, ebb and flow regarding their value and degree of fit with attitudes and circumstances based in contemporary contexts. Early 
research in art education - much of it reflective of a positivistic worldview ${ }^{20}$ that sparked an uncomfortable dissonance between experiments and measurements on one hand and idiosyncratic creative practice on the other-was not without its critics. ${ }^{21}$ But we now need to look again and more deliberately, suspending judgment about obvious limitations, and search for perhaps more subtle aspects of these works that may hold potential value for our lines of inquiry today. One such project sorely needed is a synthesis of research on creativity, the art instructional practices that foster it, and a translation of these findings for use by teachers topics that occupied many early art education researchers and are again of critical concern in today's educational worlds. ${ }^{22}$

My personal ignorance about and eventual awareness of early research that would strengthen and enrich my own gives credence to the idea that there may be some additional historical studies that are more than worth our time ferreting out. What other findings, theories, and questions from studies in our more-than-recent history are we, as contemporary researchers, unaware of? What collected knowledge and historical insights into the practices of making, responding to, teaching, and learning art and culture have we effectively erased and forgotten? How can we be sure we are not missing a key study, or theory, or even hypothesis that might profoundly inform our own work, even in some unlikely way, unless we take the time to search through the studies hidden away in vintage editions of our research journals and book publications?

If we take up the project of reviewing early research, we will need to resist the inclination to immediately dismiss as irrelevant or inferior past ideas, questions, findings, and people. We will also need to use analytical and interpretive approaches that lend themselves to open-minded and critical review, and adopt presentation forms that effectively merge past ideas and voices with our own. Kevin Tavin's (2005) citing of "palimpsestic discourse," a time-layered visual dialogue around theories and ideas that emerge in the dual action of erasing and retaining the past, is a useful strategy to consider in this pursuit. An essential source for historians in the recovery of ancient literary works, a palimpsest is, traditionally speaking, a document that has been written on repeatedly, at different times, with the earlier writing not fully erased and in part still legible, thus merging past and present ideas and voices. Tavin's own overlaying of contemporary visual culture scholarship with ideas and people that came before is the kind of conceptual connectivity with art education research history that is lacking in much of our writing today. Judith Burton's (2001) revisiting and critique of Lowenfeld's ideas, with a simultaneous uncovering and recovery of issues and contexts and the suggestion "that what one might see as omissions or difficulties ... can also be interpreted as important cautions of contemporary relevance" (p. 33), is another example. Many of the topics of early research—creativity, artistic thinking and practice, aesthetic response, art as social engagement, cultural influences on student learning, and methods of teaching, among others - are relevant to our lines of scholarly inquiry today, even if past methodologies and interpretations are necessarily expressive of different times and milieus.

conducted in the ' $70 \mathrm{~s}$ and ' 80 s on students' understanding of art history, art criticism, and aesthetics (among many others are Ecker, 1974; Erickson 1977, 1979, 1983, 1985;

Gray, 1974; Johansen, 1979) was translated by methods textbooks and many art teachers and teacher educators into a curricular move away from reliance on young people's autonomous expressive ideas as authentic creators of art, and toward teacherdirected modeling of children's art production based on the visual styles and conceptual themes of adult artists from the past. In doing so, the field did not build upon-it instead rejected-its comprehensive scholarship on children's artistic development and creative studio practice (in addition to the large body of research on creativity in young people's studio practice from the ' 50 s and ' $60 \mathrm{~s}$, see Abrahamson, 1972; Beittel, 1978; Korzenik, 1976; Kratochwill, Rush, \& Kratochwill, 1979; Packard, 1973). The DBAE movement as a whole deliberately discounted and ignored this earlier research, as exemplified here by Hamblen (1988): "In a DBAE curriculum, the emphasis is on learning art content,

(continued) 
And yet, we continue to do much more erasing than retaining of past ideas

not on students' artistic development or the conveying of original qualities in their art products. Hence, similarities among students' products are not viewed with alarm, but rather as a sign of success" (p. 23). Had research on students' responses to and understanding of art and its contexts been purposefully merged with what the field knew at the time about young people as independent, authentic, creative producers of art, the instructional outcomes of DBAE might have been quite different.

16 Baxter (1999) wrote: There is more information all the time. No one can absorb all the information. No one wants to. The day ends, not with physical exhaustion, but with data-fatigue ordatanausea ... Because there's always more information, an information explosion, but a limited capacity to absorb it or even know what information is essential and what information is trivial, anxiety often results, data-anxiety. What do you need to know, what do you need to absorb, what do you need to remember? Who can say? No one can keep up. No one is in a position to tell you (p. 146),

(continued) in our written publications of art education research. Our scholarship, while it may continue to amplify and grow in amount and volume, has not matured correspondingly in depth, sophistication, and coherence across time. We need to work toward search and recovery of forgotten scholarship-not with an uncritical, romantic sense of nostalgia, but to evaluate it from the point of view of conceptual and methodological currency — and integrate relevant ideas and voices from the past with our own as we continue the pursuit of evolving philosophies, theories, and practice-based research. As Blandy (2008), citing Lesieutre's "academic genealogies," points out:

Such exposition allows for a critique and analysis of what is exposed. In this way, scholars, and the fields of study they are associated with, can undertake a rigorous self-examination of what has shaped and is shaping them as well as what is, and is not, recognized as knowledge. Patterns of inclusion and exclusion can be noted. Conscious decisions promoting change in the future can be considered and applied. (p. 4)

How do we envision the acknowledgment and valuing of our own scholarship by future generations of art educators? Ivan Johnson, NAEA president in 1956, wrote in the preface of the 7th Yearbook:

The contents of this yearbook are "dead" unless they challenge us to study them and to utilize their findings for improvement in the teaching of art. Obviously, it is not all inclusive; many old problems are as yet unresolved and new ones appear continuously. We, as art educators, have in research a threshold for change. It should stimulate us to still further exploration and evaluation. (p. 6)

Will the contents of this "yearbook" be dead and forgotten 20 or 30 years from now? Should they be? How shall we balance necessary forgetting with remembering in our creation and documentation of collective scholarly insight in art education?

\section{References}

Abrahamson, R. (1972). The development of an instrument for measuring the degree of divergent responses revealed in clay images formed by first grade school children. Studies in Art Education, 14(1), 47-58.

Arnstine, D. (1965). Needed research and the role of definitions in art education. Studies in Art Education, 7(1), 2-17.

Barkan, M. (1957). The research committee and the nature of research in art education. Art Education, 10(5), 10-12, 20.

Barkan, M. (Ed.). (1954). Research in Art Education: NAEA 5th Yearbook. State Teachers College, Kutztown, PA: National Art Education Association.

Barkan, M. (Ed.). (1956). Research in Art Education: NAEA 7th Yearbook. State Teachers College, Kutztown, PA: National Art Education Association.

Barkan, M., \& Hausman, J. (1956). Two pilot studies with the purpose of clarifying hypotheses for research into creative behavior. Research in Art Education, 7th Yearbook (pp. 126-141). State Teachers College, Kutztown, PA: National Art Education Association.

Baxter, C. (1999). Shame and forgetting in the information age. In C. Baxter (Ed.), The business of memory: The art of remembering in an age of forgetting (pp. 141-57). St. Paul, MN: Graywolf. 
Baxter, C. (Ed.). (1999). The business of memory: The art of remembering in an age of forgetting. St. Paul, MN: Graywolf.

Beittel, K. (1961). Editorial. Studies in Art Education, 2(2), 3-6.

Beittel, K. (1978). Inquiry into the qualitative world of creating: The S-E model. Studies in Art Education, 20(1), 26-36.

Beittel, K., \& Lowenfeld, V. (1959). Interdisciplinary criteria in the arts and sciences: A progress report. Research in Art Education, 9th Yearbook (pp. 35-44). Washington, DC: National Art Education Association.

Blandy, D. (2008). Editorial: Legacies and lineages. Studies in Art Education, 50(1), 3-5.

Bolton, S. (1969). An introductory study of art as creative learning for the rural culturally disadvantaged. Studies in Art Education, 10(2), 50-56.

Bresler, L. (Ed.). (2007). International handbook of research in arts education. Dordrecht, The Netherlands: Springer.

Burton, D. (1998). Survey of current research in art education. Studies in Art Education, 39(2), 183-186.

Burton, J. (2001). Lowenfeld: An(other) look. Art Education, 54(6), 33-44.

Chalmers, G. (2006). Of Kuia and Kaumatua (Guest Editorial). Studies in Art Education, 47(4), 291-293.

Chapman, L. (1978). Editorial: Value orientations in art education theory and research. Studies in Art Education, 19(2), 4-5.

Clandinin, D., \& Connelly F. (2000). Narrative inquiry: Experience and story in qualitative research. San Francisco: Jossey-Bass.

Davis, D. (1967). Research trends in art and art education. Studies in Art Education, 20(7), 12-16.

Davis, D. (1971). Research in art education: An overview. Art Education, 24(5), 7-11.

Davis, D. (1977). Research trends in art and art education: 1883-1972. In S. Madeja (Ed.), Arts and aesthetics: An agenda for the future (pp. 109-147). St. Louis, MO: CEMREL.

Ecker, D. (1965). Editorial. Studies in Art Education, 7(1), 1.

Ecker. D. (1974). Teaching art criticism as aesthetic inquiry. Curriculum Theory Network, 4(2/3), 112-123.

Efland, E. (1971). The transition continued: The emergence of an affective revolution. Studies in Art Education, 13(1), 13-25.

Eisner, E. (1969). The drawings of the disadvantaged: A comparative study. Studies in Art Education, 11(1), 5-19.

Eisner, E., \& Day, M. (2004). Handbook of research and policy in art education. Mahwah, NJ: Erlbaum.

Elkind, D. (2007). The power of play: How spontaneous, imaginative activities lead to happier, healthier children. New York: Da Capo Press.

Erickson. M. (1977). Uses of history in art education. Studies in Art Education, 18(3), 22-29.

Erickson. M. (1979). Historical thinking and aesthetic education. Journal of Aesthetic Education, $13(4), 81-92$.

Erickson. M. (1983). Teaching art history as an inquiry process. Art Education, 36(5), 28-31.

Erickson. M. (1985). Styles of historical investigation. Studies in Art Education, 26(2), 121-124.

Fischer, T., Irons, I., \& Fischer, R. (1961). Patterns in art and science: Their creation, evolution, and correspondence. Studies in Art Education, 2(2), 85-100.

Florida, R. (2003). The rise of the creative class. New York: Basic Books.

Freyberger, R. (1956). Differences in the creative drawings of children of varying ethnic and socioeconomic backgrounds in Pennsylvania based on samplings of grades one through six. Research in Art Education, 7th Yearbook (pp. 115-125). State Teachers College, Kutztown, PA: National Art Education Association.

17 In thinking about art education research as a multi-vocal dialogue protracted over many years, it is natural for topics to attract great interest and urgency at various times, given particular social/ contextual conditionsand wane and therefore shift or "turn" at other times as conditions in the field change. My point here is that as contexts change, necessitating what we often characterize as "new" lines of inquiry, we need to look back through the extensive collection of published scholarship that preceded us to at least be aware of previous studies that may have some relevance for our "new" work.

18 For further reading on intentional and necessary cultural forgetting see Gross (2000) Lost Time: On Remembering and Forgetting in Late Modern Culture.

19 The lively debate on this topic that took place in November 2008 on the NAEA Higher Education Division list serve is evidence of this claim. David Burton (1998), in a survey of art education researchers' topics of inquiry 10 years ago, found that subjects of choice among higher education faculty and doctoral students were largely theoretical

(continued) 
in nature, and that research addressing any practical applications for teaching, curriculum, and student learning was limited to $40 \%$ for faculty research and $53 \%$ for doctoral research. However, given that the response rate for the survey was less than $25 \%$, these findings cannot be considered fully representative of the field. And, as Zimmerman (1998) has pointed out, it is impossible to know whether the studies reported were idiosyncratic, one-time investigations or part of ongoing lines of inquiry, and whether they were individual pursuits or undertaken collaboratively as part of a coordinated effort.

20 Hartman (1961) described the mission of early research efforts this way: "to provide a laboratory for the testing of educational methods derived from various theorists" (p. 4).

21 There were, at the time, insightful and impassioned critics of the nature and methods of early research, particularly those studies that used scientific and experimental methods to try to measure creative behaviors or artistic practices of young people in art class settings. Irving Kaufman, in the 1959 premiere issue of Studies in Art Education, had (continued)
Galvan, J. (2006). Writing literature reviews: A guide for students of the social and behavioral sciences (3rd ed.). Glendale, CA: Pyrczak.

Gray, J. (1974). A teaching strategy for clarifying aesthetic values. Art Education, 27(7), 11-14.

Gross, D. (2000). Lost time: On remembering and forgetting in late modern culture. Amherst, MA: University of Massachusetts Press.

Hafeli, M. (1999). Drawing and painting in the middle school: Intentions, decisions and judgments of students and their teachers. Ed.D. dissertation, Columbia University Teachers College. Retrieved January 15, 2008, from ProQuest Digital Dissertations. (Publication No. AAT 9921386).

Hafeli, M. (2000). Negotiating "fit" in student art work: Classroom conversations. Studies in Art Education, 41(2), 130-145.

Hafeli, M. (2001). Encountering student learning. Art Education, 54(6), 19-24.

Hamblen, K. (1988). What does DBAE teach? Art Education, 41(2), 23-35.

Hamblen, K. (1989). Research in art education as a form of educational consumer protection. Studies in Art Education, 31(1), 37-45.

Hamblen, K., \& Smith, S. (1994). Identifying a research art style in art education. Paper presented at the Annual Meeting of the American Educational Research Association, New Orleans, LA, April 4-8, 1994. ED 376188.

Hardiman, G., \& Zernich, T. (1976). Research in art education 1970-74: Portrayal and interpretation. Art Education, 29(2), 23-36.

Hart, C. (1998). Doing a literature review: Releasing the social science imagination. Thousand Oaks, CA: Sage.

Hartman, F. (1961). The future of research in art education. Studies in Art Education, 3(1), 4-8.

Hausman, J. (1959). Editorial. Studies in Art Education, 1(1), 3-8.

Hausman, J. (Ed.). (1959). Research in Art Education: NAEA 9th Yearbook. Washington, DC: National Art Education Association.

Hoepfner, R., Silverman, R., \& Hendricks, M. (1969). Developing and evaluating art curricula for disadvantaged youth. Studies in Art Education, 11(1), 20-33.

Hoffa, H. (1987). Research as caring skepticism. Design for Arts in Education, 88(5), 5-9.

Huberman, A., \& Miles, M. (2002). The qualitative researcher's companion. Thousand Oaks, CA: Sage.

Johansen, P. (1979). An art appreciation teaching model for visual aesthetic education. Studies in Art Education, 20(3), 4-14.

Johnson, I. (1956). Preface. Research in Art Education: NAEA 7th Yearbook. State Teachers College, Kutztown, PA: National Art Education Association.

Kennedy, M. (2007). Defining a literature. Educational Researcher, 36(3), 139-147.

Korzenik, D. (1976). Creativity: Producing solutions to a problem. Studies in Art Education, 17(2), 29-36.

Kratochwill, C., Rush, J., \& Kratochwill, T. (1979). The effects of descriptive social reinforcement on creative responses in children's easel painting. Studies in Art Education, 20(2), 29-39.

Kundera, M. (1984). The unbearable lightness of being. New York: Harper and Row.

Lanier, V. (1959). Implications of the concept of action research. Studies in Art Education, 1(1), 38-49.

Lanier, V. (1974-75). Conception and priority in art education research. Studies in Art Education, 16(1), 26-30.

Lawrence-Lightfoot, S., \& Davis, J. (1997). The art and science of portraiture. San Francisco: Jossey-Bass.

Logan, F. (1975). Up date '75: Growth in American art education. Studies in Art Education, 17(1), 7-16. 
McFee, J. (1960). Research in art education. Studies in Art Education, 2(1), 16-21.

McFee, J. (1966). Editorial. Studies in Art Education, 7(2), 1-2.

Meier, K. (1997). The value of replicating social-science research. Chronicle of Higher Education, 43(22), B7.

Montgomery, C. (1959). Creative work within a group: Its situational factors. Research in Art Education, 9th Yearbook. Washington, DC: National Art Education Association.

NAEA Commission on Research in Art Education. (1994). Art education: Creating a visual arts research agenda toward the 21st century: A final report: 1994. Art Education, 47(4), 29-44.

Neperud, R. (1969). Visual arts instruction in primitive societies: Its implications for art education. Studies in Art Education, 10(2), 12-26.

Packard, S. (1973). Creative tempo in children's art production. Studies in Art Education, 14(3), 18-26.

Paley, V. (2005). A child's work: The importance of fantasy play. Chicago: University of Chicago Press.

Rush, J. (1984). Editorial: “Does anyone read Studies any more?” Studies in Art Education, 25(3), 139-140.

Russell, I. (1956). Relationships between certain aspects of creative expression and reading development. Research in Art Education, 7th Yearbook (pp. 103-114). State Teachers College, Kutztown, PA: National Art Education Association.

Salome, R. (1968). Perceptual training in reading readiness and implications for art education. Studies in Art Education, 10(1), 58-67.

Schwandt, T. (2001). Dictionary of qualitative inquiry (2nd ed.). Thousand Oaks, CA: Sage.

Strange, M. (1940). A summary of scientific investigations relating to art. Unpublished master's thesis, Baylor University, Waco, Texas.

Tavin, K. (2005). Opening re-marks: Critical antecedents of visual culture in art education. Studies in Art Education, 47(1), 5-22.

Zimmerman, E. (1998). Further commentary: Response to Burton's Survey of Current Research in Art Education. Studies in Art Education, 39(2), 187-189.

Zimmerman, E. (Ed.) (1996). Briefing papers: Creating a visual arts research agenda toward the 21st century. Reston, VA: National Art Education Association.

Zimmerman, E., Chalmers, G., Hausman, J., \& Stockrocki, M. (2007, March). Old wine in new bottles: What is wisdom in art education? Paper presented at the meeting of the National Art Education Association, New York, NY.

this to say: The findings in these studies are singularly divorced from any real relationship to creative behavior and relative understanding of art.... The current findings... may add an iota of knowledge to educational statistics, but the quantitative analysis of art and its educational consequences do not really shed any meaningful light upon art. Nor does the supposed objective examination of the number of strokes Johnny places on a sheet of paper (that is $9 \mathrm{x}$ 12 or $18 \times 24)$ as he is emotionally stimulated by the proximity of Mary, the little blond, while manipulating a significantly small, soft brush in preference to a large, hard one, have any real bearing on the condition of creative expression (p. 11). 22 See, for example, Florida's (2003) urgent call for the fostering of a new "creative class," and Elkind's (2007) and Paley's (2005) work on the critical necessity of creative "play" in the school experiences of young people. 